\title{
Could autonomic nervous system parameters be still helpful in identifying patients with left ventricular systolic dysfunction at the highest risk of all-cause mortality?
}

Damian Kaufmann ${ }^{1}$, Grzegorz Raczak ${ }^{1}$, Małgorzata Szwoch ${ }^{1}$, Dariusz Kozłowski ${ }^{1}$, Joanna Kwiatkowska ${ }^{2}$, Ewa Lewicka ${ }^{1}$, Ludmiła Daniłowicz-Szymanowicz ${ }^{1}$

${ }^{1}$ Department of Cardiology and Electrotherapy, Medical University of Gdansk, Poland ${ }^{2}$ Department of Pediatric Cardiology and Congenital Heart Defect, Medical University of Gdansk, Poland

\begin{abstract}
Background: Autonomic imbalance is associated with poor prognosis of patients with systolic dysfunction. Most of the previous data were written several years ago and constituted to cardiovascular or arrhythmic mortality. The current treatment of these patients has improved substantially over the last decades, and thus, the population at risk of death may have altered as well. Consequently, data on high-risk patients with systolic dysfunction in the modern era are sparse and those from previous trials may no longer be applicable. The aim herein, was to verify whether well-known autonomic indices baroreflex sensitivity (BRS) and heart rate variability (HRV) - remain accurate predictors of mortality in patients with systolic dysfunction.
\end{abstract}

Methods: Non-invasively obtained BRS and HRV were analyzed in 205 clinically stable patients with left ventricular ejection fraction $(L V E F) \leq 40 \% .28$ patients died within $28 \pm 9$ month follow-up.

Results: Baroreflex sensitivity, low-frequency $(L F)$ in normalized units, $L F$ to high-frequency ratio and standard deviation of average $R$ - $R$ intervals were significantly associated with mortality; cut-off values of the highest discriminatory power for abovementioned parameters were $\leq 3.0 \mathrm{~ms} / \mathrm{mmHg}, \leq 41, \leq 0.7$ and $\leq 25 \mathrm{~ms}$, respectively. In bivariate Cox analyses (adjusted for LVEF, New York Heart Association [NYHA] or absence of implantable cardioverter-defibrillator [ICD]) autonomic indices remain significant predictors of death.

Conclusions: Baroreflex sensitivity and HRV - may still be helpful in identifying patients with left ventricular systolic dysfunction at the highest risk of all-cause mortality, independently of LVEF, NYHA class, and ICD implantation. (Cardiol J 2021; 28, 6: 914-922)

Key words: baroreflex sensitivity, heart rate variability, all-cause mortality, left ventricular dysfunction

\section{Introduction}

Heart failure (HF) is a constantly growing global pandemic, and according to the most recent data may affect between 26 and almost 38 million people worldwide $[1,2]$. Future forecasts are even more alarming, in the United States alone, morbidity due to $\mathrm{HF}$ is projected to increase from current 5.7 million to almost 8 million by 2030 [3]. Despite continuous progress in pharmacotherapy $[4,5]$, widespread use of implantable cardioverterdefibrillators (ICD) and resynchronization therapy,

Address for correspondence: Dr. Ludmiła Daniłowicz-Szymanowicz, Department of Cardiology and Electrotherapy, Medical University of Gdansk, ul. Dębinki 7, 80-952 Gdańsk, Poland, tel: +48 5834939 10, fax: +48 583493920 , e-mail: ludwik@gumed.edu.pl

Received: 3.03.2019 Accepted: 23.05.2019 Early publication date: 27.06.2019

This article is available in open access under Creative Common Attribution-Non-Commercial-No Derivatives 4.0 International (CC BY-NC-ND 4.0) license, allowing to download articles and share them with others as long as they credit the authors and the publisher, but without permission to change them in any way or use them commercially. 
all-cause mortality among patients with HF remains high $[6,7]$. Persons with significant left ventricular (LV) systolic dysfunction (LV ejection fraction $[\mathrm{LVEF}]<40 \%$ ) have the worst prognosis of all patients with $\mathrm{HF}$ [8], therefore, further evaluation, risk stratification and new therapy options for these patients remains of important clinical value. Novel treatment methods, based on autonomic nervous system (ANS) modulation [9-12], seem to be particularly promising in this context, as these treatments were shown to contribute to better quality of life and exercise capacity i.e., improvement of the New York Heart Association (NYHA) functional class and longer 6-minute walking distance. However, these beneficial effects were not associated with a decrease in all-cause mortality [9-14]. Possibly an appropriate selection of these patients, taking into account the initial ANS parameters that reveal the patients at the highest risk of all-cause mortality, could improve the results of these therapies. The majority of previous studies dealing with the ANS testing in HF constituted cardiovascular and arrhythmic mortality, and were conducted several years ago when both pharmacotherapy and electrotherapy differed substantially from those presently used [15-26]. The treatment of such individuals with HF has improved substantially over the last decades, and thus, the patient population at risk of death may have been altered as well. As a result, available data on high-risk patients with systolic dysfunction in the modern era are sparse and data from previous trials may no longer be applicable.

The aim of the present study was to verify whether simple, non-invasive autonomic parameters, such as baroreflex sensitivity (BRS) and short-term heart rate variability (HRV), could be valuable predictors of all-cause mortality in patients with significant LV systolic dysfunction, and to identify the most accurate cut-off values for these parameters.

\section{Methods}

\section{Patient selection}

In this prospective study, 205 patients with reduced LVEF $(\leq 40 \%)$ were enrolled between October 2009 and June 2014. The protocol of the study was approved by the local Ethics Committee at the Medical University of Gdansk, and written informed consent was obtained from all participants. Additional inclusion criteria: sinus rhythm, optimal pharmacological therapy, stable clinical condition for at least 3 months before enrollment, and without significant features of hypervolemia at the moment of enrollment. The patients were excluded if they were younger than 18 years old had: a history of sustained ventricular arrhythmia (ventricular tachycardia or ventricular fibrillation) or cardiac arrest, NYHA functional class IV, permanent atrial fibrillation/flutter, permanent second- or third-degree atrioventricular block, implanted pacemaker, clinical features of coronary instability at the moment of enrolment, a revascularization (coronary angioplasty or/and surgery by-pass) within 3 months prior to the study, or incomplete coronary revascularization status (scheduled control coronarography, coronary angioplasty or surgery by-pass), clinical evidence of autonomic neuropathy, concomitant terminal disease and non-cardiologic comorbidities with a potentially unfavorable effect on survival.

\section{ANS parameters}

Autonomic nervous system tests were performed according to the protocol precisely described in our previous studies $[27,28]$ with the use of Mingograf 720C for ECG and Finapres 2300 (Ohmeda) for beat-to-beat non-invasive arterial blood pressure, which was recorded continuously for $8 \mathrm{~min}$, but in comparison to abovementioned studies $[27,28]$ during breathing with a controlled interval $(0.25 \mathrm{~Hz})$. Data received were converted from analog to digital signals, processed with dedicated software [29] and analyzed according to the protocol $[15,30]$. BRS (ms/mmHg) was computed by spectral analysis exactly as it was previously described [27, 28]. Furthermore, routine HRV indices: low-frequency (LF) to high-frequency (HF) ratio $(\mathrm{LF} / \mathrm{HF})$, relative spectral powers in $\mathrm{LF}$ (LFnu expressed in normalized units), as well as time-domain HRV parameters (standard deviation of normal-to-normal RR intervals [SDNN], the square root of the mean of squared differences between successive intervals [RMSSD], and the percentage of adjacent RR intervals differing by more than $50 \mathrm{~ms}$ [pNN50]) were analyzed [16].

\section{Follow-up}

All patients were followed-up at the university outpatient clinic with the first visit scheduled within 3 months of enrolment; the patients were checked every 6 months thereafter, or earlier if clinically required. During each visit, patient clinical status was evaluated and all adverse events were recorded, if any. The primary endpoint of the study was death of any cause. All deaths were verified against medical documentation of the patient and/or death certificate information. 


\section{Statistical analysis}

The variables were expressed as medians (Q25-Q75 intervals), or numbers (n) and percentages (\%). Comparisons between dead and living patients were made by the U Mann-Whitney test, the $\chi^{2}$ test or the Yates $\chi^{2}$ test. The accuracy of analyzed parameters as potential predictors of the study end-point was determined by area (AUC) under the receiver-operating characteristic (ROC) curve. An association between analyzed parameters and the end-point was assessed using the Cox hazard models, after the dichotomization of the measurements according to their cut-off values that maximized the hazard ratio (HR). For this purpose, HR for progressively increasing appropriate values were comprised between the $20^{\text {th }}$ and $50^{\text {th }}$ percentiles (to have an adequate number of patients in each subgroup) was calculated and the point at which HR attained its maximum was identified. The time course of the end-point, stratified according to the aforementioned cut-off values, was estimated using the Kaplan-Meier method, and the association between compared groups was estimated by the log-rank test. All results were considered statistically significant at $\mathrm{p} \leq 0.05$. The statistical analysis was conducted with $\mathrm{R} 2.15 .2$ environment.

\section{Results}

Demographic, clinical and autonomic data of the group studied is presented in Table 1. Patients were approximately 63 years old, most patients had coronary artery disease and were in NYHA II class. Those with an ICD (including devices with cardiac resynchronization function) were approximately $70 \%$ of the patients. $29(14 \%)$ patients had LVEF $>35 \%$, and $36(17 \%)$ patients were in NYHA I class. Pharmacotherapy in both groups did not differ statistically. The average follow-up period was $28 \pm 9$ months, during which $28(14 \%)$ patients died, and they were characterized by significantly lower LVEF, more often presented with NYHA class III and digoxin use and less had an ICD implantation. SDNN, LFnu, LF/HF and BRS were significantly lower in patients who died in comparison to other, living patients.

\section{Predictors of all-cause mortality}

Baroreflex sensitivity was the best predictor of all-cause mortality in the studied patients (AUC $72.0 \%$ [95\% CI 61.2-82.2]), whereas other autonomic parameters and LVEF had lower discriminatory powers: AUC 67.5 [95\% CI 56.8-78.2] for SDNN, AUC 68.8\% [95\% CI 60.7-76.9] for LFnu,
AUC 69.0 [95\% CI 60.8-77.1] for LF/HF and AUC 67.9\% [95\% CI 56.8-79.1] for LVEF. The Cox-hazard regression analyses revealed that cut-off values maximally identifying patients at increased risk of death were $3.0 \mathrm{~ms} / \mathrm{mmHg}$ for BRS, 41 for LFnu, 0.7 for LF/HF, $25 \mathrm{~ms}$ for SDNN and $25 \%$ for LVEF. All these values, as well as NYHA class III, were significantly associated with the incidence of the end-point in univariate Cox analyses (Fig. 1).

The absence of ICD implantation was also a strong indicator risk of death (HR 3.21 [95\% CI 1.53-6.75], $\mathrm{p}<0.002$ ). Accuracy of the abovementioned cut-off values of BRS, LFnu, LF/HF, SDNN and LVEF in predicting the risk of death is presented in Table 2 - it was noted BRS $\leq 3.0 \mathrm{~ms} / \mathrm{mmHg}$ had the highest power in prediction of all-cause mortality in the patients studied. No other parameters from Table 1 were significant in predicting all-cause mortality in the Cox hazard regression analyses.

Kaplan-Meier curves illustrate the probability of all-cause mortality after dichotomization according to cut-off values BRS (Fig. 2), SDNN (Fig. 3), LFnu (Fig. 4) and LF/HF (Fig. 5).

Due to a relatively small number of end-points, the maximum number of predictors that could be used in a multivariate model without the risk of its overfitting was 2 . Therefore, bivariate combinations of LVEF, NYHA III and ICD presence with abovementioned cut-off values for analyzed autonomic parameters were checked: BRS, SDNN, LFnu, and $\mathrm{LF} / \mathrm{HF}$ turned-out to be independent significant predictors of the all-cause mortality (Table 3 ).

\section{Discussion}

The observation that decreased values of BRS, SDNN, LFnu and LF/HF are accurate predictors of all-cause mortality in clinically stable patients with reduced LVEF, even after adjusting for other wellknown clinical parameters (such as LVEF, NYHA class, ICD implantation) is the principal finding of the present study. The cut-off values determined in this study (BRS $\leq 3.0 \mathrm{~ms} / \mathrm{mmHg}$, SDNN $\leq 25 \mathrm{~ms}$, LFnu $\leq 41$ and $\mathrm{LF} / \mathrm{HF} \leq 0.7$ ) accurately identified patients who were at increased risk of all-cause mortality during an average 2 -year follow-up period. The novelty of the present study can be found in the demonstration that in the group of HF patients treated according to the current guidelines, in the era of widespread use of electrotherapy with ICD, the simple, non-invasive autonomic indices obtained from short-term systolic arterial pressure and electrocardiography signals are still accurate predictors of all-cause mortality. 
Table 1. Clinical and demographic characteristics of the studied patients.

\begin{tabular}{|c|c|c|c|c|}
\hline & $\begin{array}{c}\text { All } \\
(n=205)\end{array}$ & $\begin{array}{l}\text { Dead patients } \\
\quad(n=28)\end{array}$ & $\begin{array}{l}\text { Alive patients } \\
(\mathrm{n}=177)\end{array}$ & $\mathbf{P}^{*}$ \\
\hline Age [years] & $63(57-71)$ & $64(56-71)$ & $61(57-71)$ & 0.442 \\
\hline Male & $175(85 \%)$ & $25(89 \%)$ & $150(85 \%)$ & 0.771 \\
\hline CAD history & $128(62 \%)$ & $16(57 \%)$ & $112(63 \%)$ & 0.532 \\
\hline Revascularization & $129(63 \%)$ & $17(61 \%)$ & $113(64 \%)$ & 0.843 \\
\hline LVEF [\%] & $30(25-35)$ & $25(20-33)$ & $30(25-35)$ & $<0.032$ \\
\hline QRS $\geq 120 \mathrm{~ms}$ & $130(63 \%)$ & $18(64 \%)$ & $112(63 \%)$ & 1.000 \\
\hline NYHA class: & & & & $<0.041$ \\
\hline I & $36(17 \%)$ & $2(7 \%)$ & $34(19 \%)$ & \\
\hline II & $130(63 \%)$ & $16(57 \%)$ & $114(64 \%)$ & \\
\hline III & $39(19 \%)$ & $10(36 \%)$ & $29(16 \%)$ & \\
\hline Beta-adrenolytics & $197(96 \%)$ & $28(100 \%)$ & $169(95 \%)$ & 0.602 \\
\hline ACEI, ARB & $193(94 \%)$ & $26(93 \%)$ & $167(94 \%)$ & 0.668 \\
\hline Spironolactone, eplerenone & $115(56 \%)$ & $16(57 \%)$ & $99(56 \%)$ & 1.000 \\
\hline Antiplatelet therapy & $159(78 \%)$ & $22(79 \%)$ & $137(78 \%)$ & 1.000 \\
\hline Amiodarone & $21(10 \%)$ & $4(14 \%)$ & $17(10 \%)$ & 0.502 \\
\hline Statins & $163(80 \%)$ & $20(71 \%)$ & $143(81 \%)$ & 0.309 \\
\hline Digoxin & $11(5 \%)$ & $4(14 \%)$ & $7(4 \%)$ & $<0.047$ \\
\hline Diuretics & $110(54 \%)$ & $20(71 \%)$ & $90(51 \%)$ & 0.072 \\
\hline Arterial hypertension & $120(59 \%)$ & $11(39 \%)$ & $109(62 \%)$ & $<0.038$ \\
\hline Diabetes & $51(25 \%)$ & $6(21 \%)$ & $45(25 \%)$ & 0.821 \\
\hline Renal function & & & & 0.092 \\
\hline GFR $>60 \mathrm{~mL} / \mathrm{min} / 1.73 \mathrm{~m}^{2}$ & $154(75 \%)$ & $19(68 \%)$ & $135(76 \%)$ & \\
\hline GFR $30-59 \mathrm{~mL} / \mathrm{min} / 1.73 \mathrm{~m}^{2}$ & $44(21 \%)$ & $6(21 \%)$ & $38(21 \%)$ & \\
\hline $\mathrm{GFR}<30 \mathrm{~mL} / \mathrm{min} / 1.73 \mathrm{~m}^{2}$ & $7(3 \%)$ & $3(11 \%)$ & $4(2 \%)$ & \\
\hline Hypercholesterolemia & $114(56 \%)$ & $15(54 \%)$ & $99(56 \%)$ & 0.836 \\
\hline ICD & $145(71 \%)$ & $14(50 \%)$ & $131(77 \%)$ & $<0.012$ \\
\hline \multicolumn{5}{|l|}{ Autonomic parameters } \\
\hline Mean HP [ms] & 1040 (966-1133) & $996(929-1122)$ & 1050 (969-1133) & 0.071 \\
\hline SDNN [ms] & $25.8(16.6-36.5)$ & $15.0(12.2-24.4)$ & $27.2(18.2-38.0)$ & $<0.012$ \\
\hline RMSSD [ms] & $21.0(13.2-34.0)$ & $16.9(9.0-26.8)$ & $21.3(13.6-36.0)$ & 0.063 \\
\hline pNN50 [\%] & $1.84(0-11.58)$ & $0.78(0-5.24)$ & $2.31(0-13.38)$ & 0.088 \\
\hline LFnu & $32.15(15.35-52.7)$ & $17.95(11.27-28.6)$ & $35.8(17.88-57.5)$ & $<0.009$ \\
\hline $\mathrm{LF} / \mathrm{HF}$ & $0.48(0.19-1.12)$ & $0.22(0.12-0.40)$ & $0.58(0.23-1.38)$ & $<0.008$ \\
\hline $\mathrm{BRS}[\mathrm{ms} / \mathrm{mmHg}]$ & $3.89(2.24-6.55)$ & $2.28(1.51-3)$ & $4.66(2.74-7.98)$ & $<0.015$ \\
\hline
\end{tabular}

* $\mathrm{P}$ value for comparison between patients who died and alive patients. CAD - coronary artery disease; LVEF — left ventricular ejection fraction; NYHA - New York Heart Association; ACEI — angiotensin converting enzyme inhibitors; ARB - angiotensin receptor blockers GFR — glomerular filtration rate; ICD - implantable cardioverter-defibrillator; HP — heart period; SDNN - standard deviation of the average R-R intervals of the sinus rhythm; RMSSD - square root of the mean squared difference of successive R-R intervals; pNN50 - proportion of successive R-R intervals that differ by more than $50 \mathrm{~ms}$; LFnu - spectral power in low-frequency range expressed in normalized units; LF/HF LF to HF ratio; BRS - baroreflex sensitivity

In two recent studies [27, 28], the usefulness of BRS and short-term HRV in prognosis, an increased risk of hospitalization due to $\mathrm{HF}$ decompensation [27], and identification of low-arrhythmic risk patients [28] was discovered. It needs to be noted, that cut-off values for BRS established in the abovementioned
[27, 28], and other studies [15, 16, 31-33], are similar, at well-known $3.0 \mathrm{~ms} / \mathrm{mmHg}$ cut-off on BRS estimates, which presents, according to Gouveia et al. [32], a natural partition of HF patients at risk.

Noticeably, the present study showed that BRS and short-term HRV were independent 


\begin{tabular}{|c|c|c|c|c|c|}
\hline & & EVENT & Hazard ratio & $95 \% \mathrm{Cl}$ & $P$ \\
\hline LVEF [\%] & - & & 0.93 & $0.89-0.98$ & $<0.007$ \\
\hline LVEF $\leq 25 \%$ & -- & & 0.36 & $0.17-0.75$ & $<0.007$ \\
\hline NYHA III & & & 2.40 & $1.11-5.21$ & $<0.027$ \\
\hline LFnu & . & - & 0.96 & $0.94-0.99$ & $<0.004$ \\
\hline LFnu $\leq 41$ & - & & 0.15 & $0.04-0.67$ & $<0.012$ \\
\hline $\mathrm{LF} / \mathrm{HF}$ & $=$ & & 0.22 & $0.06-0.80$ & $<0.021$ \\
\hline$L F / H F \leq 0.7$ & - & & 0.15 & $0.04-0.66$ & $<0.012$ \\
\hline SDNN [ms] & - & & 0.95 & $0.91-0.99$ & $<0.022$ \\
\hline $\mathrm{SDNN} \leq 25 \mathrm{~ms}$ & $\rightarrow$ & & 0.25 & $0.09-0.70$ & $<0.008$ \\
\hline BRS $[\mathrm{ms} / \mathrm{mmHg}]$ & $\rightarrow$ & & 0.72 & $0.57-0.91$ & $<0.005$ \\
\hline $\mathrm{BRS} \leq 3.0 \mathrm{~ms} / \mathrm{mmHg}$ & $=$ & & 0.19 & $0.07-0.51$ & $<0.001$ \\
\hline
\end{tabular}

Figure 1. The Cox hazard regression analysis for pre-specified cut-off values of analyzed parameters as predictors of all-cause mortality during follow-up period; $\mathrm{Cl}$ - confidence interval; LVEF — left ventricular ejection fraction; NYHA — New York Heart Association functional class; LFnu - spectral power in low-frequency range expressed in normalized units; LF/HF — low-frequency to high-frequency ratio; SDNN — standard deviation of average R-R intervals of sinus rhythm; BRS — baroreflex sensitivity.

Table 2. Prognostic accuracy of the cut-off values of BRS, LFnu, LF/HF, SDNN, LVEF and NYHA III as predictors of death.

\begin{tabular}{|c|c|c|c|c|c|}
\hline \multirow[t]{2}{*}{ Parameters } & \multirow[t]{2}{*}{ AUC (\%) } & \multicolumn{2}{|c|}{$\begin{array}{c}\text { Characteristics (\%) } \\
(95 \% \mathrm{Cl})\end{array}$} & \multicolumn{2}{|c|}{$\begin{array}{l}\text { Predictive value (\%) } \\
\qquad(95 \% \mathrm{Cl})\end{array}$} \\
\hline & & Sensitivity & Specificity & Positive & Negative \\
\hline LVEF $\leq 25 \%$ & 62.4 & $\begin{array}{c}53.57 \\
(35.81-70.47)\end{array}$ & $\begin{array}{c}71.19 \\
(64.12-77.35)\end{array}$ & $\begin{array}{c}22.73 \\
(14.29-34.17)\end{array}$ & $\begin{array}{c}90.65 \\
(84.66-94.45)\end{array}$ \\
\hline NYHA III & 60.0 & $\begin{array}{c}47.71 \\
(20.71-54.17)\end{array}$ & $\begin{array}{c}83.62 \\
(77.46-88.34)\end{array}$ & $\begin{array}{c}25.64 \\
(14.57-41.08)\end{array}$ & $\begin{array}{c}89.16 \\
(83.51-93.03)\end{array}$ \\
\hline $\mathrm{BRS} \leq 3.0 \mathrm{~ms} / \mathrm{mmHg}$ & 72.0 & $\begin{array}{c}76.19 \\
(54.91-89.37)\end{array}$ & $\begin{array}{c}67.80 \\
(58.92-75.55)\end{array}$ & $\begin{array}{c}29.63 \\
(19.14-42.83)\end{array}$ & $\begin{array}{c}94.12 \\
(86.96-97.46)\end{array}$ \\
\hline $\mathrm{SDNN} \leq 25 \mathrm{~ms}$ & 67.5 & $\begin{array}{c}75.00 \\
(53.13-88.81)\end{array}$ & $\begin{array}{c}60.00 \\
(51.06-68.32)\end{array}$ & $\begin{array}{c}23.81 \\
(14.99-35.64)\end{array}$ & $\begin{array}{c}93.51 \\
(85.68-97.19)\end{array}$ \\
\hline LFnu $\leq 41$ & 68.8 & $\begin{array}{c}90.00 \\
(69.90-97.21)\end{array}$ & $\begin{array}{c}47.50 \\
(38.78-56.37)\end{array}$ & $\begin{array}{c}22.22 \\
(14.54-32.42)\end{array}$ & $\begin{array}{c}96.61 \\
(88.46-99.07)\end{array}$ \\
\hline $\mathrm{LF} / \mathrm{HF} \leq 0.7$ & 69.0 & $\begin{array}{c}90.00 \\
(69.90-97.21)\end{array}$ & $\begin{array}{c}47.90 \\
(39.13-56.80)\end{array}$ & $\begin{array}{c}22.50 \\
(14.73-32.79)\end{array}$ & $\begin{array}{c}96.61 \\
(88.46-99.07)\end{array}$ \\
\hline
\end{tabular}

AUC - area under the receiver-operating characteristic (ROC) curve; Cl - confidence interval; LVEF — left ventricular ejection fraction; NYHA - New York Heart Association functional class; BRS - baroreflex sensitivity; SDNN - standard deviation of the average R-R intervals of the sinus rhythm; LFnu — spectral power in low-frequency range expressed in normalized units; LF/HF — low-frequency to high-frequency ratio

risk factors of death regardless of LVEF and NYHA class, and, even more importantly, irrespective of ICD use, which can be considered a particularly important and novel finding. In the light of current discussions in the literature on the validity of ICD implantation in all patients with LV systolic dysfunction [34, 35], as well as in light of new methods of treatment of HF patients based on ANS modulation, the analyses presented in this paper seem to be of particular clinical significance.
In comparison to two recent studies [27, 28], in the present paper, BRS and HRV estimation were performed during breathing with a controlled interval $(0.25 \mathrm{~Hz})$, which is well-known methodological modification allowing the exclusion of the breathing rate influences on spontaneous BRS and HRV parameters in HF patients [36, 37].

\section{Limitations of the study}

There are potential limitations in the present study. Firstly, this was a small, single-center study, 


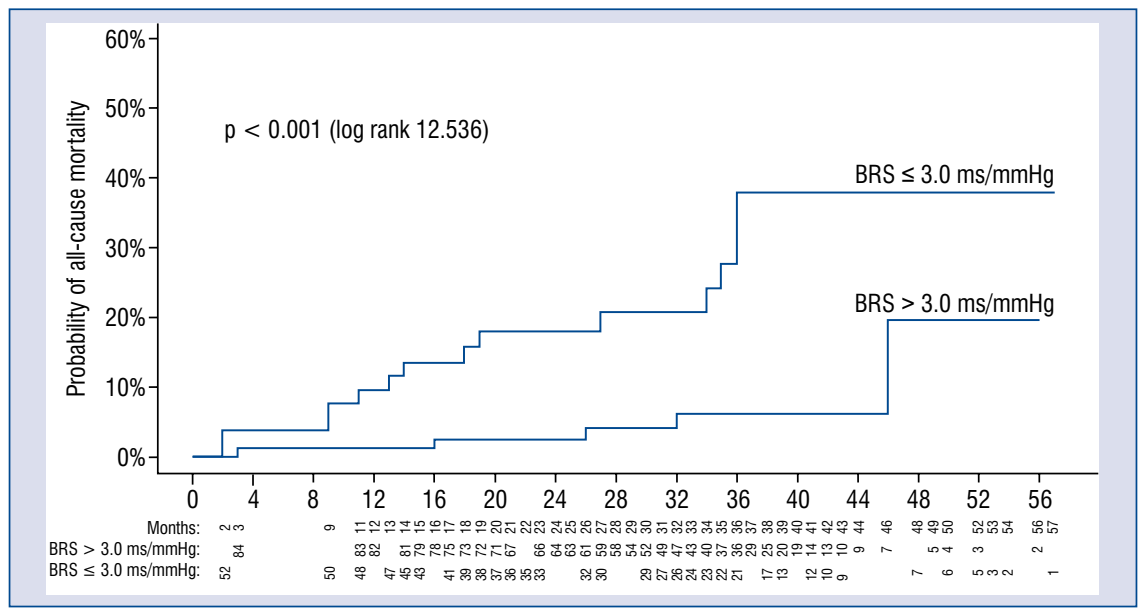

Figure 2. Kaplan-Meier curves illustrating the probability of the EVENT during the follow-up period depending on prespecified cut-off values for baroreflex sensitivity (BRS).

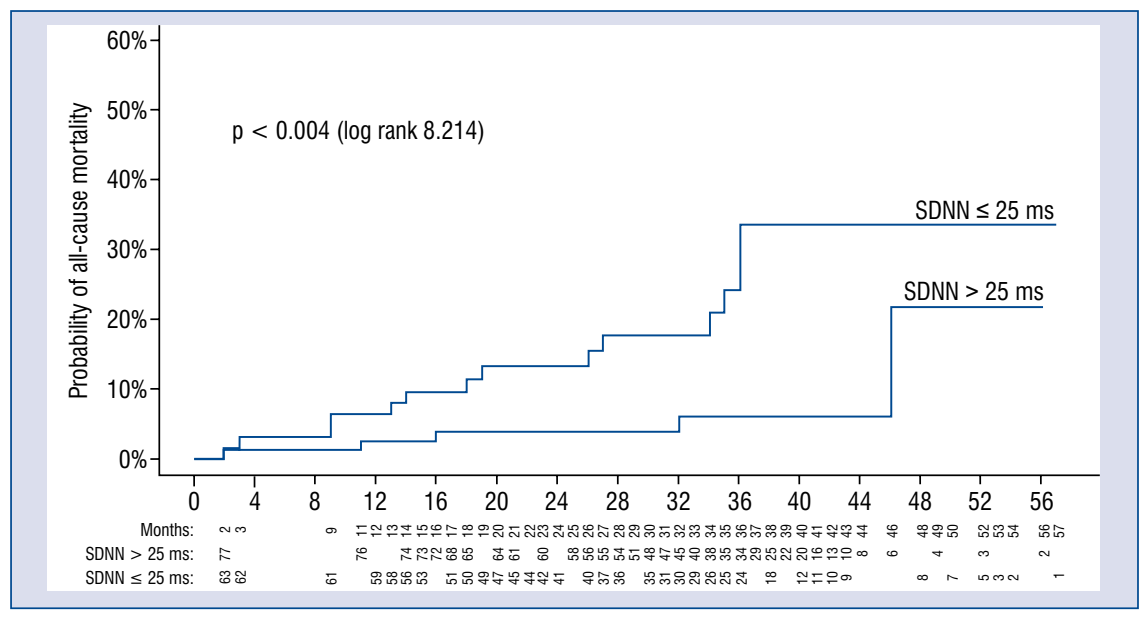

Figure 3. Kaplan-Meier curves illustrating the probability of the EVENT during follow-up period depending on prespecified cut-off values for standard deviation of the average R-R intervals of the sinus rhythm (SDNN).

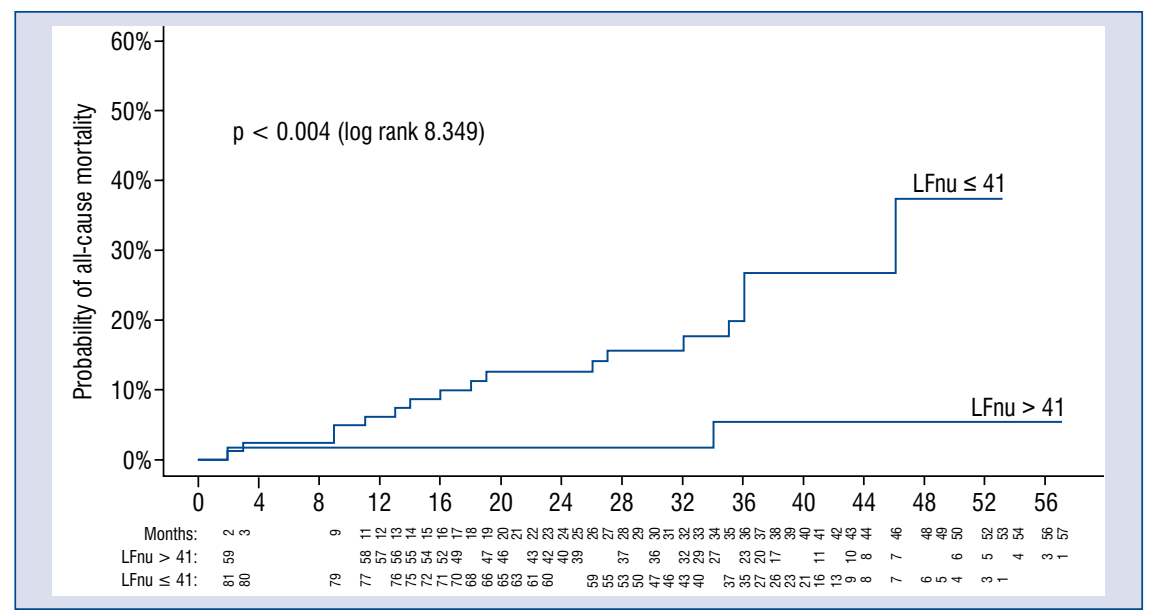

Figure 4. Kaplan-Meier curves illustrating the probability of the EVENT during follow-up period depending on prespecified cut-off values for spectral power in low-frequency range expressed in normalized units (LFnu). 


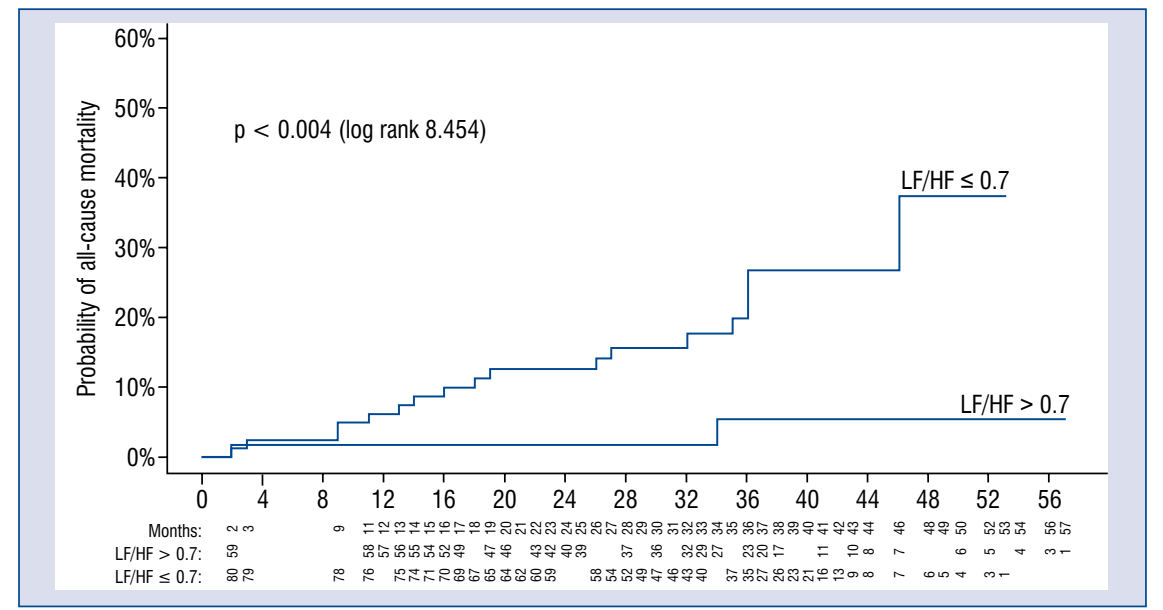

Figure 5. Kaplan-Meier curves illustrating the probability of the EVENT during follow-up period depending on prespecified cut-off values for low-frequency to high-frequency ratio (LF/HF).

Table 3. Bivariate Cox models for EVENTs for BRS and HRV indexes during follow-up period (adjusted to LVEF, NYHA III, or presence of ICD).

\begin{tabular}{lccc}
\hline & Hazard ratio & $\mathbf{9 5 \%} \mathbf{C l}$ & $\mathbf{P}$ \\
\hline LVEF-adjusted HR for BRS $\leq 3.0 \mathrm{~ms} / \mathrm{mmHg}$ & 6.52 & $2.36-17.96$ & $<\mathbf{0 . 0 0 0 1}$ \\
LVEF-adjusted HR for SDNN $\leq 25 \mathrm{~ms}$ & 3.68 & $1.32-10.25$ & $<\mathbf{0 . 0 1 3}$ \\
LVEF-adjusted HR for LF/HF $\leq 0.7$ & 6.18 & $1.43-26.73$ & $<\mathbf{0 . 0 1 5}$ \\
LVEF-adjusted HR for LFnu $\leq 41$ & 6.12 & $1.42-26.50$ & $<\mathbf{0 . 0 1 5}$ \\
NYHA III-adjusted HR for BRS $\leq 3.0 \mathrm{~ms} / \mathrm{mmHg}$ & 5.24 & $1.92-14.36$ & $<\mathbf{0 . 0 0 1}$ \\
NYHA III-adjusted HR for SDNN $\leq \mathbf{2 5} \mathrm{ms}$ & 3.77 & $1.37-10.40$ & $<\mathbf{0 . 0 1 0}$ \\
NYHA III-adjusted HR for LF/HF $\leq 0.7$ & 5.67 & $1.29-24.81$ & $<\mathbf{0 . 0 2 1}$ \\
NYHA III-adjusted HR for LFnu $\leq 41$ & 5.61 & $1.28-24.57$ & $<\mathbf{0 . 0 2 2}$ \\
ICD-adjusted HR for BRS $\leq 3.0 \mathrm{~ms} / \mathrm{mmHg}$ & 5.48 & $2.01-14.99$ & $<\mathbf{0 . 0 0 0 1}$ \\
ICD-adjusted HR for SDNN $\leq \mathbf{2 5} \mathrm{ms}$ & 3.88 & $1.41-10.70$ & $<\mathbf{0 . 0 0 9}$ \\
ICD-adjusted HR for LF/HF $\leq 0.7$ & 6.56 & $1.52-28.33$ & $<\mathbf{0 . 0 1 2}$ \\
ICD-adjusted HR for LFnu $\leq 41$ & 6.52 & $1.51-28.15$ & $<\mathbf{0 . 0 1 2}$ \\
\hline
\end{tabular}

$\mathrm{Cl}$ - confidence interval; LVEF - left ventricular ejection fraction; BRS - baroreflex sensitivity; SDNN - standard deviation of the average R-R intervals of sinus rhythm; LFnu - relative spectral power in LF range, expressed in normalized units; LF/HF - low-frequency to highfrequency ratio; NYHA - New York Heart Association functional class; ICD — implantable cardioverter-defibrillator

with a relatively short follow-up period; the results need to be confirmed in a larger group of patients with a longer observation periods. Secondly, some patients, apart from the fact that they were clinically stable, were not optimally treated concerning the three groups of drugs (ACEI/ARB, BB and MRA): some of them due to the significant contraindications or intolerance symptoms, another reason could be connected with the period of enrollment, which took place a few years ago and since then there has been further progress in pharmacologi- cal treatment of patients with HF. Additionally, the authors did not analyse the influence of diuretics doses on mortality. The next limitation concerns BRS and HRV indices, which were not possible to measure in the patients with permanent atrial fibrillation/flutter, permanent second- or thirddegree atrioventricular block, and persons with paced rhythm; these patients are at the high risk of death, therefore further investigations concerning the prognosis of all-cause mortality amongst all HF patients with reduced LVEF are still needed. 


\section{Conclusions}

The results of the present study suggest that simple, non-invasively obtained parameters of ANS activity, such as BRS and short-term HRV (SDNN, LFnu and LF/HF), remains helpful in the identification of persons with increased risk of all-cause mortality amongst clinically stable patients with LV systolic dysfunction treated in line to current guidelines, even after adjusting for other basic clinical parameters, such as LVEF, NYHA class, and ICD implantation.

\section{Conflict of interest: None declared}

\section{References}

1. Ponikowski P, Anker SD, AlHabib KF, et al. Heart failure: preventing disease and death worldwide. ESC Heart Fail. 2014; 1(1): 4-25, doi: 10.1002/ehf2.12005, indexed in Pubmed: 28834669.

2. Vos T, Flaxman AD, Naghavi M, et al. Years lived with disability (YLDs) for 1160 sequelae of 289 diseases and injuries 1990-2010: a systematic analysis for the Global Burden of Disease Study 2010. Lancet. 2012; 380(9859): 2163-2196, doi: 10.1016/S01406736(12)61729-2, indexed in Pubmed: 23245607.

3. Mozaffarian D, Benjamin E, Go A, et al. Heart Disease and Stroke Statistics—2016 Update. Circulation. 2016; 133(4), doi: 10.1161/ cir.0000000000000350.

4. Ponikowski P, Voors A, Anker S, et al. 2016 ESC Guidelines for the diagnosis and treatment of acute and chronic heart failure. European Journal of Heart Failure. 2016; 18(8): 891-975, doi: 10.1002/ejhf.592.

5. Tomaszuk-Kazberuk A, Bolińska S, Młodawska E, et al. Does admission anaemia still predict mortality six years after myocardial infarction? Kardiol Pol. 2014; 72(6): 488-493, doi: 10.5603/ KP.a2014.0046, indexed in Pubmed: 24526561.

6. Murad K, Goff DC, Morgan TM, et al. Burden of Comorbidities and Functional and Cognitive Impairments in Elderly Patients at the Initial Diagnosis of Heart Failure and Their Impact on Total Mortality: The Cardiovascular Health Study. JACC Heart Fail. 2015; 3(7): 542-550, doi: 10.1016/j.jchf.2015.03.004, indexed in Pubmed: 26160370.

7. Mozaffarian D, Benjamin EJ, Go AS, et al. Heart disease and stroke statistics--2015 update: a report from the American Heart Association. Circulation. 2015; 131(4): e29-322, doi: 10.1161/ CIR.0000000000000152, indexed in Pubmed: 25520374.

8. Meta-analysis Global Group in Chronic Heart Failure (MAGGIC). The survival of patients with heart failure with preserved or reduced left ventricular ejection fraction: an individual patient data meta-analysis. Eur Heart J. 2011; 33(14): 1750-1757, doi: 10.1093/eurhearti/ehr254.

9. Premchand RK, Sharma K, Mittal S, et al. Autonomic regulation therapy via left or right cervical vagus nerve stimulation in patients with chronic heart failure: results of the ANTHEM-HF trial. J Card Fail. 2014; 20(11): 808-816, doi: 10.1016/j.cardfail.2014.08.009, indexed in Pubmed: 25187002.

10. Zannad F, De Ferrari GM, Tuinenburg AE, et al. Chronic vagal stimulation for the treatment of low ejection fraction heart failure: results of the NEural Cardiac TherApy foR Heart Fail- ure (NECTAR-HF) randomized controlled trial. Eur Heart J. 2015; 36(7): 425-433, doi: 10.1093/eurheartj/ehu345, indexed in Pubmed: 25176942.

11. Abraham W, Zile M, Weaver F, et al. Baroreflex activation therapy for the treatment of heart failure with a reduced ejection fraction. JACC: Heart Failure. 2015; 3(6): 487-496, doi: 10.1016/j. jchf.2015.02.006.

12. Gronda E, Seravalle G, Brambilla G, et al. Chronic baroreflex activation effects on sympathetic nerve traffic, baroreflex function, and cardiac haemodynamics in heart failure: a proof-of-concept study. Eur J Heart Fail. 2014; 16(9): 977-983, doi: 10.1002/ ejhf.138, indexed in Pubmed: 25067799.

13. De Ferrari GM, Stolen C, Tuinenburg AE, et al. Long-term vagal stimulation for heart failure: Eighteen month results from the NEural Cardiac TherApy foR Heart Failure (NECTARHF) trial. Int J Cardiol. 2017; 244: 229-234, doi: 10.1016/j.ijcard.2017.06.036, indexed in Pubmed: 28663046.

14. Gold M, Veldhuisen DV, Hauptman P, et al. Vagus Nerve Stimulation for the Treatment of Heart Failure. J Am Coll Cardiol. 2016; 68(2): 149-158, doi: 10.1016/j.jacc.2016.03.525.

15. Pinna GD, Maestri R, Capomolla S, et al. Applicability and clinical relevance of the transfer function method in the assessment of baroreflex sensitivity in heart failure patients. J Am Coll Cardiol. 2005; 46(7): 1314-1321, doi: 10.1016/j.jacc.2005.06.062, indexed in Pubmed: 16198850.

16. Camm AJ, Bigger JT, Breithardt G, et al. Heart rate variability. Standards of measurement, physiological interpretation, and clinical use. Task Force of the European Society of Cardiology and the North American Society of Pacing and Electrophysiology. Eur Heart J. 1996; 93(5): 1043-1065.

17. La Rovere MT, Bigger JT, Marcus FI, et al. Baroreflex sensitivity and heart-rate variability in prediction of total cardiac mortality after myocardial infarction. ATRAMI (Autonomic Tone and Reflexes After Myocardial Infarction) Investigators. Lancet. 1998; 351(9101): 478-484, doi: 10.1016/s0140-6736(97)11144-8, indexed in Pubmed: 9482439.

18. La Rovere MT, Pinna GD, Maestri R, et al. Prognostic implications of baroreflex sensitivity in heart failure patients in the beta-blocking era. J Am Coll Cardiol. 2009; 53(2): 193-199, doi: 10.1016/j.jacc.2008.09.034, indexed in Pubmed: 19130988.

19. La Rovere MT, Maestri R, Robbi E, et al. Comparison of the prognostic values of invasive and noninvasive assessments of baroreflex sensitivity in heart failure. J Hypertens. 2011; 29(8): 1546-1552, doi: 10.1097/HJH.0b013e3283487827, indexed in Pubmed: 21666492.

20. Perkiömäki JS, Hämekoski S, Junttila MJ, et al. Predictors of long-term risk for heart failure hospitalization after acute myocardial infarction. Ann Noninvasive Electrocardiol. 2010; 15(3): 250-258, doi: 10.1111/j.1542-474X.2010.00372.x, indexed in Pubmed: 20645968.

21. Raczak G, Pinna GD, Maestri R, et al. Different predictive values of electrophysiological testing and autonomic assessment in patients surviving a sustained arrhythmic episode. Circ J. 2004; 68(7): 634-638, indexed in Pubmed: 15226627.

22. La Rovere MT, Pinna GD, Maestri R, et al. Short-term heart rate variability strongly predicts sudden cardiac death in chronic heart failure patients. Circulation. 2003; 107(4): 565-570, indexed in Pubmed: 12566367.

23. La Rovere MT, Pinna GD, Maestri R, et al. Autonomic markers and cardiovascular and arrhythmic events in heart failure patients: still a place in prognostication? Data from the GISSI-HF 
trial. Eur J Heart Fail. 2012; 14(12): 1410-1419, doi: 10.1093/ eurjhf/hfs126, indexed in Pubmed: 22851700.

24. Nolan J, Batin P, Andrews R, et al. Prospective study of heart rate variability and mortality in chronic heart : results of the United Kingdom heart failure evaluation and assessment of risk trial (UK- heart). Circulation. 1998; 98(15): 1510-1516, doi: 10.1161/01.cir.98.15.1510.

25. Ponikowski P, Anker SD, Chua TP, et al. Depressed heart rate variability as an independent predictor of death in chronic congestive heart failure secondary to ischemic or idiopathic dilated cardiomyopathy. Am J Cardiol. 1997; 79(12): 1645-1650, indexed in Pubmed: 9202356.

26. Powell BD, Saxon LA, Boehmer JP, et al. Survival after shock therapy in implantable cardioverter-defibrillator and cardiac resynchronization therapy-defibrillator recipients according to rhythm shocked. The ALTITUDE survival by rhythm study. J Am Coll Cardiol. 2013; 62(18): 1674-1679, doi: 10.1016/j. jacc.2013.04.083, indexed in Pubmed: 23810882.

27. Daniłowicz-Szymanowicz L, Suchecka J, Niemirycz-Makurat A, et al. Autonomic Predictors of Hospitalization Due to Heart Failure Decompensation in Patients with Left Ventricular Systolic Dysfunction. PLoS One. 2016; 11(3): e0152372, doi: 10.1371/ journal.pone.0152372, indexed in Pubmed: 27015089.

28. Daniłowicz-Szymanowicz L, Kaufmann D, Rozwadowska K, et al. Microvolt T-wave alternans and autonomic nervous system parameters can be helpful in the identification of low-arrhythmic risk patients with ischemic left ventricular systolic dysfunction. PLoS One. 2018; 13(5): e0196812, doi: 10.1371/journal. pone.0196812, indexed in Pubmed: 29723261.

29. Maestri R, Pinna G. POLYAN: A computer program for polyparametric analysis of cardio-respiratory variability signals. Comput Methods Programs Biomed. 1998; 56(1): 37-48, doi: 10.1016/ s0169-2607(98)00004-2.

30. Pinna GD, Maestri R, Raczak G, et al. Measuring baroreflex sensitivity from the gain function between arterial pressure and heart period. Clin Sci (Lond). 2002; 103(1): 81-88, doi: 10.1042/, indexed in Pubmed: 12095408.

31. Ranucci M, Porta A, Bari V, et al. Baroreflex sensitivity and outcomes following coronary surgery. PLoS One. 2017; 12(4): e0175008, doi: 10.1371/journal.pone.0175008, indexed in Pubmed: 28384188.

32. Gouveia S, Scotto MG, Pinna GD, et al. Spontaneous baroreceptor reflex sensitivity for risk stratification of heart failure patients: optimal cut-off and age effects. Clin Sci (Lond). 2015; 129(12): 1163-1172, doi: 10.1042/CS20150341, indexed in Pubmed: 26432088.

33. Schwartz PJ, La Rovere MT, De Ferrari GM, et al. Autonomic modulation for the management of patients with chronic heart failure. Circ Heart Fail. 2015; 8(3): 619-628, doi: 10.1161/CIRCHEARTFAILURE.114.001964, indexed in Pubmed: 25991804.

34. Køber L, Thune JJ, Nielsen JC, et al. Defibrillator Implantation in Patients with Nonischemic Systolic Heart Failure. N Engl J Med. 2016; 375(13): 1221-1230, doi: 10.1056/NEJMoa1608029, indexed in Pubmed: 27571011.

35. Haugaa KH, Tilz R, Boveda S, et al. Implantable cardioverter defibrillator use for primary prevention in ischaemic and nonischaemic heart disease-indications in the post-DANISH trial era: results of the European Heart Rhythm Association survey. Europace. 2017; 19(4): 660-664, doi: 10.1093/europace/eux089, indexed in Pubmed: 28431077.

36. Rahman F, Pechnik S, Gross D, et al. Low frequency power of heart rate variability reflects baroreflex function, not cardiac sympathetic innervation. Clin Auton Res. 2011; 21(3): 133-141, doi: 10.1007/s10286-010-0098-y, indexed in Pubmed: 21279414.

37. Harada D, Asanoi H, Takagawa J, et al. Slow and deep respiration suppresses steady-state sympathetic nerve activity in patients with chronic heart failure: from modeling to clinical application. Am J Physiol Heart Circ Physiol. 2014; 307(8): H1159-H1168, doi: 10.1152/ajpheart.00109.2014, indexed in Pubmed: 25128165. 